\title{
Study on Indoor Environment Evaluation and Reconstruction Strategy of Existing Public Buildings in Hot Summer and Cold Winter Zone
}

\author{
Y.T. Ma ${ }^{1, a^{*}}$, J.T. Weng ${ }^{1, b}$ \\ ${ }^{1}$ Room 506, Crescent Building, Zijingang Campus of Zhejiang University, Xihu District, Hangzhou \\ City, Zhejiang Province, China \\ a412617504@qq.com, b815895960@qq.com
}

\begin{abstract}
Keywords: Hot summer and cold winter zone; Existing public buildings; Indoor environmental evaluation; Reconstruction strategy

Abstract: This paper analyzes the importance of the indoor environment of existing public buildings based on the present situation. Through the experiment the paper puts up the objective index of typical existing public building's indoor environment in hot summer and cold winter zone and subjective evaluation of PMV-PPD. On the basis of the experimental results, the strategy of the indoor environment improvement is put forward, which provides the theoretical basis and strategic guidance for the reform of existing public buildings.
\end{abstract}

\section{Introduction}

Energy is the important basis for the survival and development of human beings and the driving force of the world economic operation ${ }^{[1]}$. The global economy, production, construction and other aspects can't be separated from the supply of energy. Nowadays, the building energy consumption in China has accounted for $30 \%$ of the total energy consumption of the society ${ }^{[2]}$. Therefore, the research and practice of building energy efficiency is an indispensable part of building scientific research, which is related to the concept of "green", "energy conservation", "sustainable development", "environmental protection" and so on.

China is the largest developing country in the world. According to statistics ${ }^{[3]}$, the housing construction area of towns and villages in China has reached about 53 Billions square meters. The annual new construction area has reached 15-20 millions square meters. Per area heating energy consumption is similar to 2-3 times of the developed countries with similar climate conditions. Therefore, it is one of the main directions of the future research for both building energy consumption and indoor environment.

Public building is one of the main types of buildings used in daily life. The indoor environment during the main use time of public buildings (9:00-20:00) should be controlled in the range of people's comfort. At the same time, the monitoring of the indoor environment quality to public buildings and subjective evaluation of users are the keys of the research on the building environment physics.

This paper selects Crescent Building which is one of the most important public buildings in Zijingang Campus of Zhejiang University as the object of study and experiment, monitors the indoor environmental data, analyses and puts forward the conclusions which are related to the human thermal comfort, proposes the reconstruction strategy of existing public buildings. The paper provides theoretical basis and technical support for the reconstruction of existing buildings.

\section{Zhejiang University as an example}

Purpose and object of experiment. In order to study and evaluate the situation of the indoor thermal environment of existing public buildings in hot summer and cold winter zone, this paper selects Crescent Building, Zijingang Campus of Zhejiang University, Xihu District, Hangzhou City, Zhejiang Province, China as the research object, selects people's active time 6:30-20:30 in a typical public building during the transition season. The most commonly used classroom is chose as the main 
experimental test site in Crescent Building. Temperature, relative humidity, instantaneous wind speed, radiation temperature, PMV-PPD and other objective data are measured in the experiment.

Contents and methods of experiment. The experimental equipment is the Testo174 temperature and humidity recorder and the thermal comfort measuring instrument.

There are five Indoor test points. Point 1 is located in the center of the classroom and point 2-5 are located around the classroom (Fig.1). The height of the test points is controlled at $1.2 \mathrm{~m}$. These five points can be comparative analyzed in the horizontal and vertical dimensions respectively.
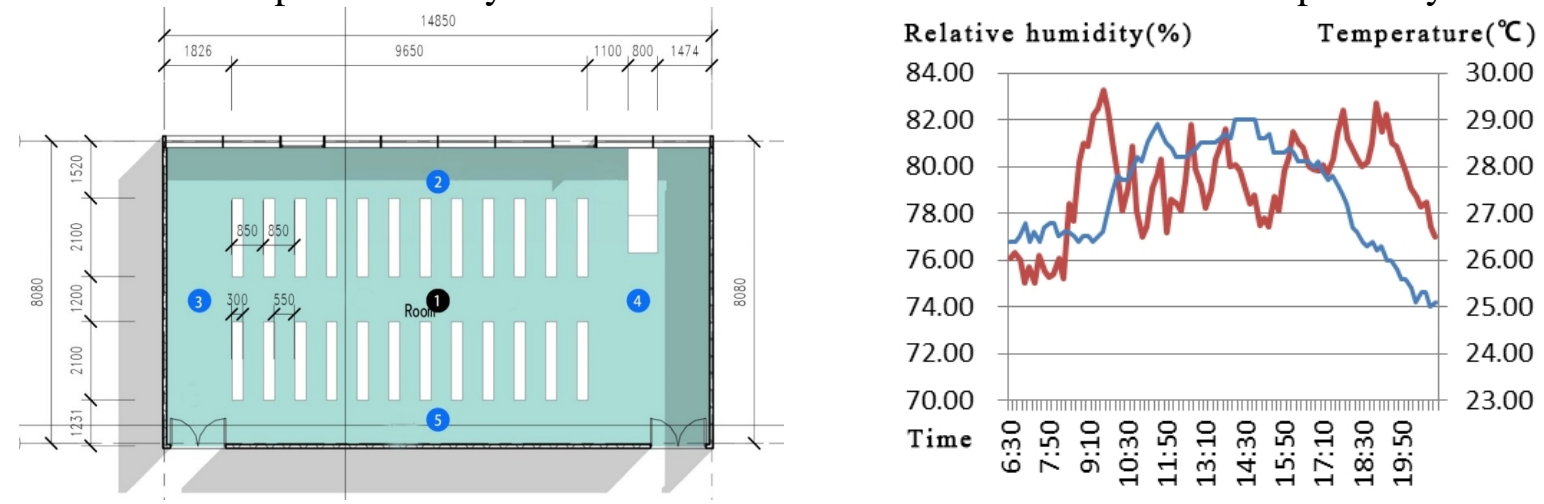

Fig.1 Test points' horizontal distribution in the classroom of Crescent Building
Fig.2 Range of temperature and relative humidity in the classroom of Crescent Building

Data and conclusions of experiment. In dealing with the indoor temperature and relative humidity data, through averaging the five test points' temperature and relative humidity, the experiment concludes the specific situation of the temperature and relative humidity changes of indoor environment. (Fig.2)

The indoor temperature is controlled in the $25.00-29.00^{\circ} \mathrm{C}$. The average value is $27.38^{\circ} \mathrm{C}$. The amplitude is $4^{\circ} \mathrm{C}$. It is in a reasonable range of fluctuations and in accordance with the basic conditions for the transition of human thermal comfort. If we need to lower the indoor temperature and reach the human thermal comfort for more hight requirement, we should improve the construction of external shading.

The indoor relative humidity is controlled in $75.00-83.30 \%$, the average value is $79.28 \%$. The amplitude is $8.30 \%$. It is in a reasonable range in hot summer and cold winter zone. However, from the picture it can be found, the relative humidity fluctuation is very frequent in the day, and its stability is to be further strengthened. We should improve the sealing of doors and windows

In processing the instantaneous wind speed data, through averaging the instantaneous wind speeds of the five test points, it is concluded the range of the temperature and humidity in the indoor environment (Fig.3). The range of the instantaneous wind speed is $0.05-0.25 \mathrm{~m} / \mathrm{s}$ in Crescent Building. The peak of the wind speed is controlled at about $0.2 \mathrm{~m} / \mathrm{s}$ at times. It is accord with China's 《 Assessment standard for green building $》{ }^{[4]}$ within the comfortable range. Because of the impact of the surrounding environment, plant configuration, accidental factors and so on, there will be the possibility of sudden changes in the indoor wind speed. In order to reduce or avoid the occurrence of this situation, it can improve the plant and other aspects in the reconstruction of the existing public buildings.

In processing the radiation temperature data, through averaging the radiation temperature of the five test points, it is concluded the range of the radiation temperature in the indoor environment (Fig.4). Data show that the range of the radiation temperature is $24-29^{\circ} \mathrm{C}$, the highest temperature is $28.4^{\circ} \mathrm{C}$ at 14:30 which is roughly accord with the change of the solar irradiance. 


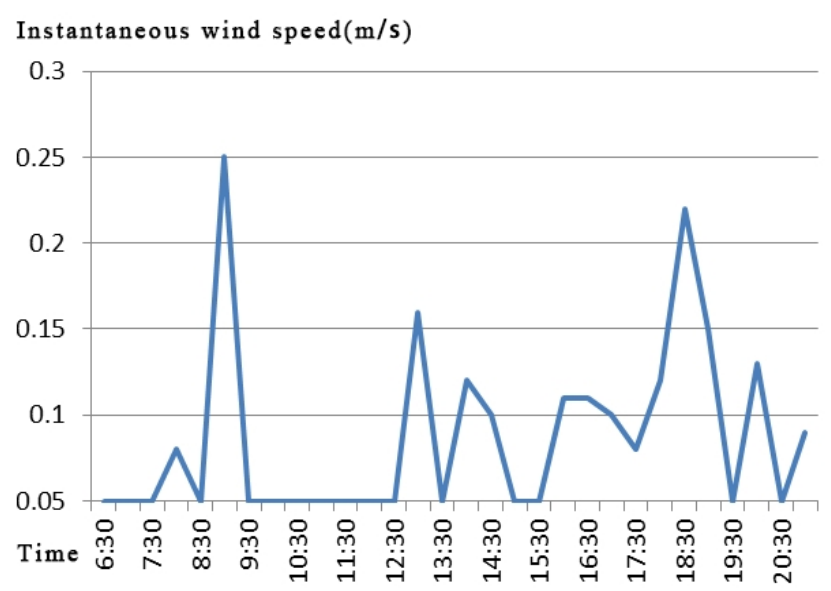

Fig.3 Range of the instantaneous wind speed in the classroom of Crescent Building

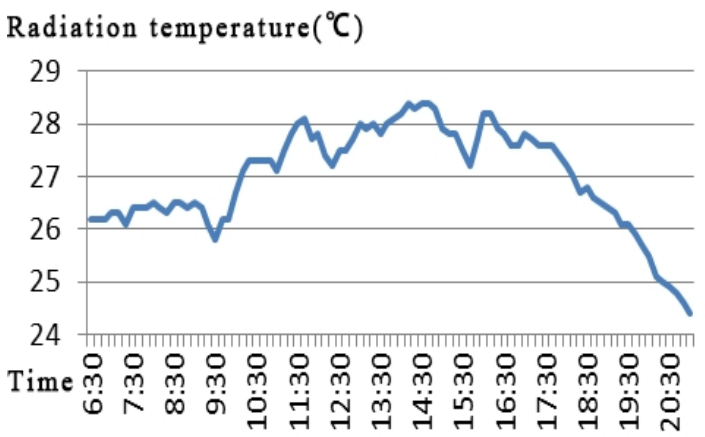

Fig.4 Range of the radiation temperature in the classroom of Crescent Building

From Fig.5, 6 it can be seen that the indoor PMV ranges in 0.2-1.8. PPD is high during the main working time (10:00-16:00), the peak of PPD is $70 \%$ when there is no active device system. It is related to the materials of the building envelope and the sunshade component in the existing public buildings. It is need to consider these measures in the process of reconstruction.

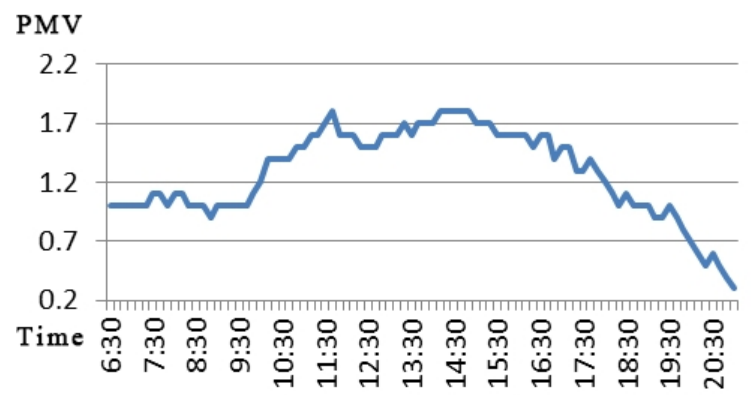

Fig.5 Range of PMV in the classroom of Crescent Building

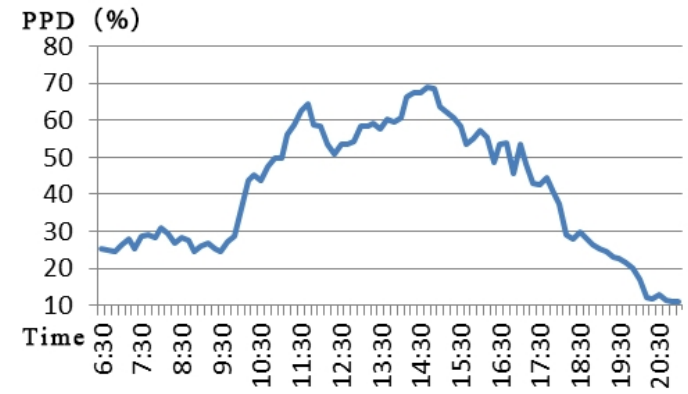

Fig.6 Range of PPD in the classroom of Crescent Building

\section{Reconstruction strategy for the indoor environment in the existing public buildings}

According to the objective actuality and subjective evaluation of the indoor environment, it is necessary to reform the public buildings. There should be a series of feasible reconstruction strategy. (Table 1)

Table 1 Relativity between the reconstruction strategy and the indoor environment index

\begin{tabular}{|c|c|c|c|c|}
\hline & Temperature & $\begin{array}{c}\text { Relative } \\
\text { humidity }\end{array}$ & $\begin{array}{c}\text { Instantaneous } \\
\text { wind speed }\end{array}$ & $\begin{array}{c}\text { Radiation } \\
\text { temperature }\end{array}$ \\
\hline Outdoor-plant & $\sqrt{ }$ & $\sqrt{ }$ & $\sqrt{ }$ & \\
\hline Outdoor-ground material & & & & $\sqrt{ }$ \\
\hline Envelope-wall & $\sqrt{ }$ & & & $\sqrt{ }$ \\
\hline Envelope-window & $\sqrt{ }$ & & $\sqrt{ }$ & \\
\hline Envelope-sunshade component & & & & $\sqrt{ }$ \\
\hline Indoor-furniture & & & $\sqrt{ }$ & \\
\hline Indoor-air deflector & & & $\sqrt{ }$ & \\
\hline
\end{tabular}

\section{Reconstruction strategy of outdoor environment}

(1) Plant. The density and height of the plants play important parts in the outdoor environment, which can reduce the indoor temperature and the instantaneous wind speed. In addition, it can adjust the relative humidity of the indoor environment and improve the environment comfort. 
(2) Ground material. The purpose of reconstructing the outdoor hard ground is to make the sun's radiant heat which is absorbed by the hard ground transfer downward as soon as possible, so as to reduce the heat which is reflected from the ground to the facade. It can be achieved by changing the thermal inertia coefficient of the ground material. ${ }^{[5]}$

\section{Reconstruction strategy of the envelope}

(1) Wall. It can reduce indoor temperature and radiation temperature and be a building facade design by painting the wall light and planting some climbing vine outside the wall. These two methods are not high in the cost and process requirements and have a high feasibility.

(2) Window. Window is a part of the building envelope which transfers the heat quickly. If we want to improve the stability of the temperature and humidity, we must choose the window which has good air tightness to deal with the sudden changes of the instantaneous wind speed.

(3) Sunshade component. Sunshade component is the most effective measure in the summer heat insulation. It reflects and absorbs most of the solar energy and avoids the solar radiant heat going inside. It is beneficial to prevent temperature from increasing and fluctuating. It plays an important role in improving the indoor thermal comfort and reducing air conditioning energy consumption. ${ }^{[6]} \mathrm{By}$ adding sunshade component and window curtains, it can control the solar radiation inside the building. Reconstruction strategy of indoor layout

(1) Furniture. Suitable furniture arrangement and position are advantageous to the stability of the indoor instantaneous wind speed

(2) Air deflector. It is conducive to control the direction and size of indoor air.

\section{Conclusions}

Existing public buildings is one of the essential buildings in people's life. The indoor environment quality and the subjective evaluation of the user are the important contents of building physics. Through analyzing the existing public buildings and doing experimental research, this paper obtains the reconstruction strategy of the outdoor environment, building envelope and indoor environment feasibly. It has important theoretical significance and practical value.

\section{Acknowledgments}

This research was supported by Project in the National Science \& Technology Pillar Program during the Twelfth Five-year Plan Period (Project name: Evaluation and optimization of building energy consumption system \& Research and demonstration of self-insulation system, Project number: 2011BAJ03B11)

\section{References}

[1] Z.M. Jiang, Thought on China's energy issues, Journal of Shanghai Jiao Tong University. 42 (2008) 345-359.

[2] Z.G. Zhang, R. Chang, Y. Li, Introduction to building energy efficiency, Tianjin, China,2011.

[3] Ministry of Housing and Urban-Rural Development of the People's Republic of China, Statistical bulletin of urban and rural construction,2014.

[4] Ministry of Housing and Urban-Rural Development of the People's Republic of China, Assessment standard for green building, 2015.

[5] T.T. Sheng, Energy-saving strategy for the existing residential building in hot summer and cold winter zone, Master degree thesis of Zhejiang University, 2010.

[6] W. Zhang, S.M. Zhang, Sunshade and energy efficiency in buildings, Hua Zhong Architecture. 22 (2004) 86-88. 
